\title{
Myocardial deformation after radiotherapy: a layer-specific and territorial longitudinal strain analysis in a cohort of left-sided breast cancer patients (BACCARAT study)
}

Valentin Walker ${ }^{1}$, Olivier Lairez ${ }^{2,3,4}$, Olivier Fondard ${ }^{5}$, Gaëlle Jimenez ${ }^{6}$, Jérémy Camilleri ${ }^{6}$, Loïc Panh ${ }^{7}$, David Broggio ${ }^{8}$, Marie-Odile Bernier ${ }^{1}$, Dominique Laurier ${ }^{9}$, Jean Ferrières ${ }^{2,10,11}$ and Sophie Jacob ${ }^{1 *}$ (D)

\begin{abstract}
Background: Radiotherapy for breast cancer (BC) and its resulting cardiac exposure are associated with subclinical left ventricular dysfunction characterized by early decrease of global longitudinal strain (LS) measurement based on 2D speckle-tracking echocardiography. Recent software allows multi-layer and segmental analysis of strain, which may be of interest to quantify and locate the impact of cardiac exposure on myocardial function and potentially increase the early detection of radiation-induced cardiotoxicity. The aim of the study was to evaluate whether decrease in LS 6 months after radiotherapy is layer-specific and if it varies according to the left ventricular regional level and the coronary arterial territories.
\end{abstract}

Methods: LS was measured at baseline before radiotherapy and 6 months post-radiotherapy. The LS was obtained for each myocardial layer (endocardial, mid-myocardial, epicardial), left ventricular regional level (basal, mid, apical) and coronary artery territory (left anterior descending artery (LAD), circumflex artery, right coronary artery).

Results: The study included 64 left-sided BC patients. Mean age was 58 years, mean doses to the heart, the left ventricle and the LAD were respectively 3.0, 6.7 and $16.4 \mathrm{~Gy}$. The absolute decrease of LS was significant for the three layers (endocardial: $-20.0 \pm 3.2 \%$ to $-18.8 \pm 3.8 \%$; mid-myocardial: $-16.0 \pm 2.7 \%$ to $-15.0 \pm 3.1 \%$; epicardial: $-12.3 \pm 2.5 \%$ to $-11.4 \pm 2.8 \%$, all $p=$ $0.02)$, but only the relative decrease of $L S$ in the endocardial layer was close to be significant $(-4.7 \%, p=0.05)$. More precisely, the LS of the endocardial layer was significantly decreased for the most exposed parts of the left ventricle corresponding to the apical level $(-26.3 \pm 6.0 \%$ vs. $-24.2 \pm 7.1 \%, p=0.03)$ and LAD territory $(-22.8 \pm 4.0 \%$ vs. $-21.4 \pm 4.8 \%, p=0.03)$.

Conclusion: Six months post-radiotherapy, LS decreased predominantly in the endocardial layer of the most exposed part of the left ventricle. For precise evaluation of radiotherapy-induced cardiotoxicity and early left ventricular dysfunction, the endocardial layer-based LS might be the most sensitive parameter.

Trial registration: ClinicalTrials.gov: NCT02605512, Registered 6 November 2015 - Retrospectively registered.

Keywords: Radiation therapy, Cardiac toxicity, Echocardiography, Multilayer strain, Coronary arteries

\footnotetext{
*Correspondence: sophie.jacob@irsn.fr

${ }^{1}$ Pôle Santé-Environnement (PSE-SANTE), Service de recherche sur les effets

biologiques et sanitaires des rayonnements ionisants (SESANE), Laboratoire

d'épidémiologie des rayonnements ionisants (LEPID), Institute for

Radiological Protection and Nuclear Safety (IRSN), BP17, 92262

Fontenay-aux-Roses cedex, France

Full list of author information is available at the end of the article
}

C C The Author(s). 2020 Open Access This article is licensed under a Creative Commons Attribution 4.0 International License, which permits use, sharing, adaptation, distribution and reproduction in any medium or format, as long as you give appropriate credit to the original author(s) and the source, provide a link to the Creative Commons licence, and indicate if changes were made. The images or other third party material in this article are included in the article's Creative Commons licence, unless indicated otherwise in a credit line to the material. If material is not included in the article's Creative Commons licence and your intended use is not permitted by statutory regulation or exceeds the permitted use, you will need to obtain permission directly from the copyright holder. To view a copy of this licence, visit http://creativecommons.org/licenses/by/4.0/. The Creative Commons Public Domain Dedication waiver (http://creativecommons.org/publicdomain/zero/1.0/) applies to the data made available in this article, unless otherwise stated in a credit line to the data. 


\section{Background}

Radiotherapy (RT) is a major component of breast cancer treatment. Despite its benefits, it is now commonly accepted that breast cancer RT can be associated with long-term cardiac complications, including coronary artery diseases, due to the presence of cardiac tissues in the irradiation field [13]. Long before the onset of clinically detectable cardiac events, sensitive parameters of left ventricular myocardial dysfunction based on echocardiography can be investigated. Two-dimensional speckle-tracking echocardiography is a semi-automated quantitative technique for assessment of strain, a measure of myocardial deformation to evaluate the myocardial systolic function. Global longitudinal strain (LS) is often considered as an optimal parameter of deformation for the early detection of sub-clinical left ventricular dysfunction $[4,5]$. Many studies on early myocardial dysfunction after BC RT showed a significant decrease in global LS among left-sided breast cancer patients at different times post-RT, from few weeks to 3 years [6-14], whereas no measurable alteration of left ventricular ejection fraction (LVEF) was observed. Moreover, some previous works showed an association between the global LS decrease after $\mathrm{BC}$ RT and the mean heart dose or the mean left ventricular dose [15].

However, the left ventricular wall of the heart is composed of three myocardial layers: endocardial, midmyocardial, and epicardial. Of these 3 layers, the endocardial layer is the most susceptible of ischemic injury
[16] and potentially radiotherapy-induced subclinical ischemic injury. Recent softwares allow multi-layer strain analysis $[17,18]$, but separate evaluation of endocardial, mid-myocardial and epicardial myocardial deformation has never been analyzed in breast cancer patients treated with RT. A careful evaluation of these layers, in particular the endocardial layer, might increase the early detection of radiation-induced cardiotoxicity in this context.

Cardiac exposure due to breast cancer RT is not homogeneous [19]. Highest cardiac radiation doses are likely to be delivered to the anterior part of the heart and the left ventricle, including the left anterior descending coronary artery (LAD), and are observed in the apex and in the apical-anterior segment where some hot spots $>50$ Gy can be found [20]. One study based on strain imaging detected a correlation between the reduction in regional myocardial function (basal level, mid-level and apical level) and the local radiation dose [10] as the decrease in global LS at the apical level was the most important. Heterogeneity of doses among coronary arteries was also demonstrated [19, 21], but it was never considered for LS analysis whereas left ventricular segmentations provide segmental strains that can be assigned to coronary arterial territories [22]. Thus, analysis of territorial myocardial function (LAD, circumflex artery $(\mathrm{Cx})$ and right coronary artery (RCA)) might also be relevant in the context of early detection of RT-induced cardiotoxicity.

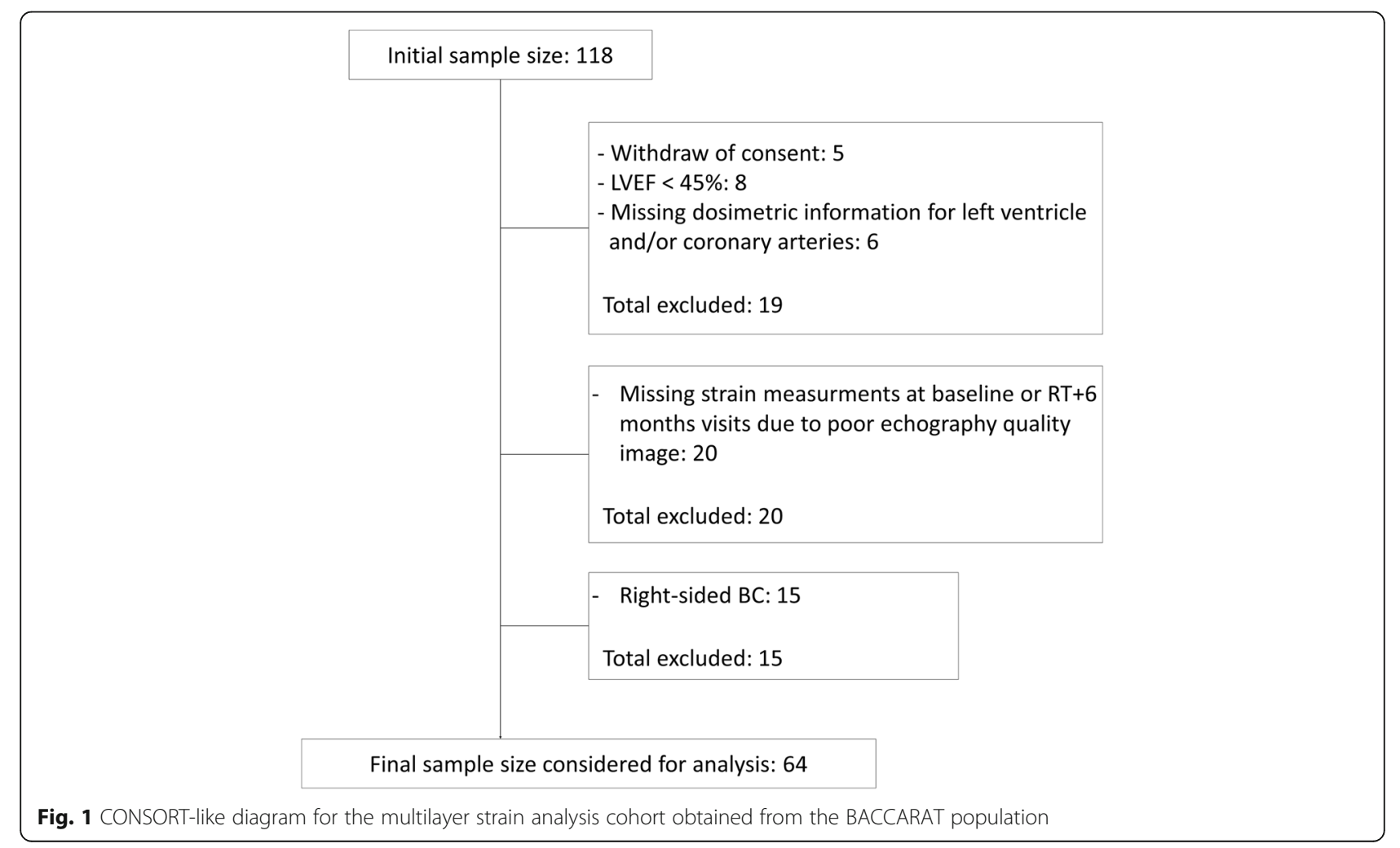


Based on the BACCARAT prospective cohort of left and right $\mathrm{BC}$ patients treated with $3 \mathrm{D}-\mathrm{CRT}$, we had presented a 6-month interim follow-up analysis on a secondary outcome measure defined by a decrease of global LS from baseline to 6 months after RT [15]. In the continuation of these previous results, the aim of this new paper was to evaluate among left-sided $\mathrm{BC}$ patients whether this decrease in global LS at the scale of the left ventricle was myocardial layer-specific, depending on regional level and coronary arterial territories, and whether coronary arteries doses were associated with territorial strain changes.

\section{Patients and methods}

\section{Study population}

The BACCARAT study initially included 118 female patients of the Clinic Pasteur Toulouse from October 2015 to December 2017, aged 40 to 75 years old, mainly with left unilateral $\mathrm{BC}$, and in a smaller proportion with rightsided unilateral BC. All patients were treated with adjuvant 3D-CRT after breast conserving surgery or mastectomy, without chemotherapy. Five patients withdrew consent, 8 patients had abnormal LVEF before RT (LVEF $<45 \%)$ and 6 patients without available cardiac dosimetry were excluded. We excluded patients with echocardiographies for which the image quality was too low for a reliable assessment of longitudinal strain $(n=20)$ remaining 79 patients [15, 23]. For the analysis presented here, we focused on left-sided BC patients, and finally, the patient study group consisted of 64 patients (Fig. 1). With a follow-up of 6-months after RT, none of the 64 patients included had undergone chemotherapy.

\section{Radiotherapy treatment and radiation doses evaluation} All patients were treated with 3D-CRT. The prescription dose was delivered over 5 weeks: either 50 Gy in 25 daily fractions of $2 \mathrm{~Gy}$ or $47 \mathrm{~Gy}$ in 20 daily fractions of $2.35 \mathrm{~Gy}$. The methods to evaluate radiation doses in BACCARAT patients were presented elsewhere $[15,19,23]$. DoseVolume-Histogram $(\mathrm{DVH})$ for the heart was generated by the Clinic Pasteur radiotherapy department. Before RT, a coronary computed tomography angiography (CCTA) was performed for all patients as planned in the BACCARAT protocol. For dosimetric evaluation of coronary arteries, the simulation CT scan, the CCTA, the RT dose and RT structure files in DICOM format were used. Merging anatomical information from the simulation CT scan and the CCTA was performed. Once inserted in ISOgray TPS (version 4.2, Dosisoft, Cachan, France; http://www.dosisoft. com/en/radiotherapy/planning-products.html), manual delineation was performed for the left ventricle (LV), the left anterior descending artery (LAD), the left circumflex artery $(\mathrm{Cx})$ and the right coronary artery (RCA). Using the $3 \mathrm{D}$ dose matrix generated during treatment planning and the new delineated substructures, DVH for LV and coronary arteries were generated with ISOgray TPS by the dosimetric department of IRSN in collaboration with the Clinic Pasteur radiotherapy department. We thus obtained mean doses for the following cardiac structures: whole heart, left ventricle, left anterior descending artery, circumflex artery and right coronary artery.

\section{Transthoracic echocardiography}

Transthoracic echocardiography was performed at baseline before RT and 6 months after RT with ultrasound Acuson S2000 device (Siemens Medical Solutions USA, Inc. Malvern, USA), using a $3 \mathrm{MHz}$ transducer. Image analysis was independently performed by a single blinded observer unaware of clinical data. Longitudinal strain (LS) measurement was evaluated using two-dimensional speckle tracking [24] using a 16-segment model as

\section{6 segment model}

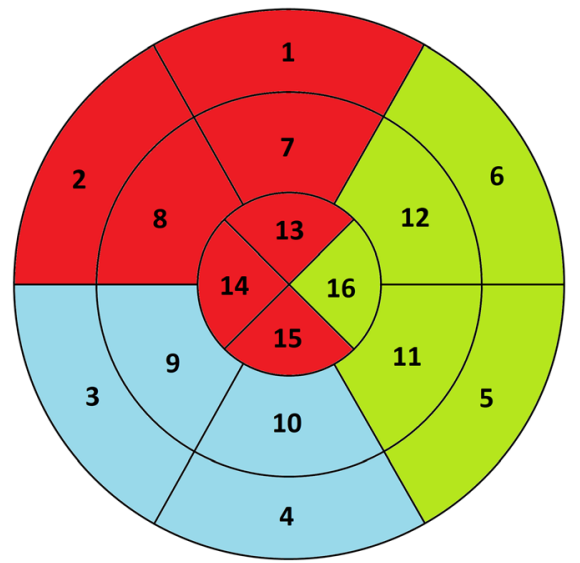

1. Basal Anterior

2. Basal anteroseptal

9. Mid inferolateral

3. Basal Inferoseptal

10. Mid inferior

4. Basal Inferior

11. Mid inferolateral

12. Mid anterolateral

5. Basal inferolateral

13. Apical anterior

Basal anterolateral

14. Apical septal

15. Apical inferior

7. Mid anterior

16. Apical lateral

Arterial distribution considered in BACCARAT

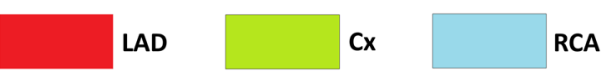

Fig. 2 "Bull-eye" presentation of the left ventricle: 16-segmental model and coronary artery territories. Legend: LAD - Left Anterior Descending artery; Cx - Circumflex artery; RCA - Right Coronary Artery 
recommended by the American Society of Echocardiography guidelines [25]. Global LS for the whole left ventricle was obtained for each myocardial layer (endocardial, mid-myocardial and epicardial). Mean LS for each regional level (basal, mid and apical) and for each coronary artery territory (Territorial Longitudinal Strain (TLS) LAD, TLS Cx and TLS RCA) [22] was calculated as the mean of segmental LS included in these levels (Fig. 2). In particular, the specific LS corresponding to the segments of the LAD (TLS LAD), was based on the average of segments 1, 2, 7, 8, 13, 14 and 15 as indicated in Fig. 2.

\section{Statistical analysis}

Continuous variables are presented with mean and standard deviation or median and interquartile range values. Categorical values are presented with percentages. Student's $t$-test or Wilcoxon non-parametric test was used to compare continuous variables, adapted to paired samples for the comparison of echocardiographic variables before RT and 6 months after RT. Comparison of layer-specific LS at baseline and RT +6 months were performed, mean relative change was evaluated (Mean $=\mathrm{V} 6-\mathrm{V0} / \mathrm{V0})$. Specific analysis of segmental strains values according to regional level or coronary arteries territorial areas was performed, and the evolution of LS in these levels from baseline to $\mathrm{RT}+6$ months was analyzed. We compared these evolutions according to the group of exposure ("High" for patients with cardiac doses $>66$ th percentile of dose distribution, "Low" for others). Given the exploratory nature of this work, we presented unadjusted $p$-values for comparisons, but in order to take into account multiple testing in these comparisons we also applied the Holm-Bonferroni method, a step-down procedure performed after conducting the multiple comparison tests. Finally, $p$-value $<0.05$ was considered statistically significant. All statistical analysis was performed using SAS statistical software for Windows (Version 9.4 TS1M4 - SAS Institute, Cary, NC).

\section{Results}

\section{Study population}

Sixty-four left-sided breast cancer patients were included in the analysis. Baseline characteristics of the population are shown in Table 1. The mean age at inclusion was $58 \pm$ 9 years. Concerning cardiac risk factors, 14 (22\%), 20 (31\%) and 28 (44\%) patients had hypertension, hypercholesterolemia and a BMI over $25 \mathrm{~kg} / \mathrm{m}^{2}$, respectively. Moreover, $8 \%$ of patients had diabetes, and $47 \%$ were current smokers. The mean dose received by the left ventricle was more than twice as high as the mean dose received by the whole heart $(6.68 \pm 3.36$ versus $3.05 \pm 1.31, P=<0.0001)$. For coronary arteries exposure, the highest mean dose was found in the LAD $(16.41 \pm 7.41 \mathrm{~Gy})$, while the lowest mean dose was found in the RCA $(0.71 \pm 0.37 \mathrm{~Gy})$.
Table 1 Baseline characteristics of the study population

\begin{tabular}{|c|c|}
\hline & $\begin{array}{l}\text { Left-sided BC } \\
\text { patients } \boldsymbol{n}=64\end{array}$ \\
\hline Age in years, mean $\pm S D$ & $58 \pm 9$ \\
\hline \multicolumn{2}{|l|}{ Type of cancer, $n(\%)$} \\
\hline In situ & $11(17 \%)$ \\
\hline Invasive & $53(83 \%)$ \\
\hline \multicolumn{2}{|l|}{ Surgery, n (\%) } \\
\hline Breast conserving & $61(95 \%)$ \\
\hline Mastectomy & $3(54 \%)$ \\
\hline Regional lymph node irradiation & $22(34 \%)$ \\
\hline Supraclavicular alone & 1 \\
\hline Internal mammary alone & 2 \\
\hline Both & 19 \\
\hline Body mass index in $\mathrm{kg} / \mathrm{m}^{2}$, mean $\pm S D$ & $24.5 \pm 4.2$ \\
\hline \multicolumn{2}{|l|}{ Smoking, n (\%) } \\
\hline Never-smokers & $34(53 \%)$ \\
\hline Former smokers & $20(31 \%)$ \\
\hline Current smokers & $10(16 \%)$ \\
\hline Systolic blood pressure, in $\mathrm{mmHg}$, mean $\pm \mathrm{SD}$ & $119 \pm 12$ \\
\hline Diastolic blood pressure in $\mathrm{mmHg}$, mean $\pm \mathrm{SD}$ & $75 \pm 10$ \\
\hline Hypertension, n (\%) & $14(22 \%)$ \\
\hline Diabetes, n (\%) & $5(8 \%)$ \\
\hline Hypercholesterolemia, n (\%) & $20(31 \%)$ \\
\hline \multicolumn{2}{|l|}{ Cardiac doses in Gy } \\
\hline \multicolumn{2}{|l|}{ Whole Heart } \\
\hline Mean \pm SD & $3.05 \pm 1.31$ \\
\hline Min - Max & $0.87-6.37$ \\
\hline \multicolumn{2}{|l|}{ Left Ventricle } \\
\hline Mean \pm SD & $6.68 \pm 3.36$ \\
\hline Min - Max & $1.16-13.42$ \\
\hline \multicolumn{2}{|l|}{ Left Descending Artery } \\
\hline Mean \pm SD & $16.41 \pm 7.41$ \\
\hline Min - Max & $1.68-34.63$ \\
\hline \multicolumn{2}{|l|}{ Circumflex Artery } \\
\hline Mean \pm SD & $1.65 \pm 0.82$ \\
\hline Min - Max & $0.53-4.34$ \\
\hline \multicolumn{2}{|l|}{ Right Coronary Artery } \\
\hline Mean \pm SD & $0.71 \pm 0.37$ \\
\hline Min - Max & $0.14-2.50$ \\
\hline
\end{tabular}

$B C$ Breast Cancer, SD Standard Deviation

Multilayer evolution of the global longitudinal strain

Echocardiography parameters are displayed in Table 2. Left ventricular ejection fraction (LVEF) remained within normal range after RT. A significant decrease in global longitudinal strain was observed for each myocardial layer, but the highest mean relative change from baseline to $\mathrm{RT}+6$ 
Table 2 Comparison of baseline and follow-up measurements of echocardiographic data

\begin{tabular}{|c|c|c|c|c|}
\hline & Baseline $\boldsymbol{n}=64$ & 6 months after RT $\boldsymbol{n}=64$ & $\boldsymbol{P}$-value & Relative change (\%) $\boldsymbol{p}$-value \\
\hline LVEF, \% & $61 \pm 7$ & $60 \pm 9$ & 0.073 & $\mathrm{Na}$. \\
\hline \multicolumn{5}{|l|}{ GLS, \% } \\
\hline Endocardial layer & $-20.0 \pm 3.2$ & $-18.8 \pm 3.8$ & 0.02 & $-4.7 \% ; 0.05$ \\
\hline Mid-myocardial layer & $-16.0 \pm 2.7$ & $-15.0 \pm 3.1$ & 0.02 & $-4.4 \% ; 0.11$ \\
\hline Epicardial layer & $-12.3 \pm 2.5$ & $-11.4 \pm 2.8$ & 0.02 & $-4.2 \% ; 0.25$ \\
\hline
\end{tabular}

LVEF Left Ventricular Ejection Fraction, GLS Global Longitudinal Strain, Na. Not assessed

months was observed in the endocardial layer $(-4.7 \%, p=$ $0.05)$ whereas for other layers, the mean relative change was slightly lower.

\section{Left ventricular regional evolution of the longitudinal strain in the endocardial layer}

Among the three regional left ventricular levels, a significant decrease of the LS was observed only in the apical level $(-26.3 \pm 6.0 \%$ vs. $-24.2 \pm 7.1 \%, p=0.03)$. After Holm-Bonferroni method for multiple testing for 3 tests, this decrease did not reach statistical significance. While separating patients into two groups according to their exposure to the left ventricle (Table 3 ), the regional analysis showed that LS decreased significantly after RT at the apical level in the highly exposed group corresponding to the 22 patients with LV Dose $>66$ th percentile $=$ $8.6 \mathrm{~Gy}(-25.5 \pm 6.3$ at V0 to $-22.7 \pm 6.9$ at V6; $p=0.04)$, which did not remain significant after multiple testing correction. More precisely, the segmental analysis of strain values (Fig. 3) showed a decrease in all segments of the apical level, with significant deteriorations in the apical inferior segment (segment 15) and the midanteroseptal segment (segment 8), but not significant after Holm-Bonferroni method.

\section{Coronary arteries territorial evolution of the endocardial} layer longitudinal strain

The coronary arteries territorial analysis showed no significant decrease for the $\mathrm{Cx}$ and the RCA. However, an alteration of the LS was observed for the LAD territory ($22.8 \pm 4.0 \%$ vs. $-21.4 \pm 4.8 \%, p=0.03$ ). While separating patients into two groups according to their exposure to the left ventricle (Table 4), an alteration of the LS was observed for the LAD territory in the highly exposed group corresponding to patients receiving $>8.6 \mathrm{~Gy}$ to the $\mathrm{LV}(-22.7 \pm 3.4$ at $\mathrm{V} 0$ to $-20.7 \pm 4.5$ at V6; $p=0.05$ ).

Moreover, longitudinal strain decrease in the LAD territory could be associated with the dose level of the LAD with a significant decrease observed in the highly exposed group corresponding to the 22 patients with LAD Dose $>66$ th percentile $=19.9 \mathrm{~Gy}(p=0.02)$, and this result remained significant after Holm-Bonferroni method for 2-tests comparisons. No significant difference could be observed in less exposed patients, corresponding to a decrease of LS from $-22.3 \%$ at V0 to $-19.5 \%$ at V6 (Fig. 4). In comparison, no significant difference could be observed for the Cx and the RCA at the highest exposures, even by taking into account the precise dose to these substructures (Figs. 5 and 6).

\section{Discussion}

At the scale of the whole left ventricle, the previously reported deterioration of LS 6 months after BC RT [15], is confirmed on the three layers of the myocardial wall. However, our study suggests that the LS strain change may be more relevant in the endocardial layer, in particular in the most exposed areas of the left ventricle, corresponding to the apical region and the LAD territory.

Table 3 Regional analysis of longitudinal strains in the endocardial layer

\begin{tabular}{|c|c|c|c|c|c|}
\hline & & \multicolumn{2}{|c|}{ Low dose to the LV $\boldsymbol{n}=42$} & \multicolumn{2}{|c|}{ High dose to the LV $\boldsymbol{n}=22$} \\
\hline & & V0 & V6 & V0 & V6 \\
\hline \multirow[t]{2}{*}{ Basal level, \% } & Mean \pm SD & $-16.7 \pm 5.6$ & $-17.1 \pm 5.0$ & $-19.0 \pm 3.5$ & $-17.8 \pm 3.2$ \\
\hline & $p$-value & 0.52 & & 0.10 & \\
\hline \multirow[t]{2}{*}{ Mid-level, \% } & Mean \pm SD & $-18.6 \pm 3.0$ & $-17.0 \pm 5.2$ & $-17.6 \pm 3.4$ & $-17.5 \pm 4.7$ \\
\hline & $p$-value & 0.06 & & 0.90 & \\
\hline \multirow[t]{2}{*}{ Apical level, \% } & Mean \pm SD & $-26.7 \pm 5.8$ & $-25.0 \pm 7.2$ & $-25.5 \pm 6.3$ & $-22.7 \pm 6.9$ \\
\hline & $p$-value & 0.18 & & $0.04^{\mathrm{a}}$ & \\
\hline
\end{tabular}

LV Left Ventricle. Low dose to the LV corresponds to patients receiving < 8.6 Gy to the LV (66th percentile of dose distribution among the 64 patients). High dose to the LV corresponds to patients receiving $>8.6 \mathrm{~Gy}$. ${ }^{\mathrm{N}}$ Not significant after Holm-Bonferroni method for multiple testing 


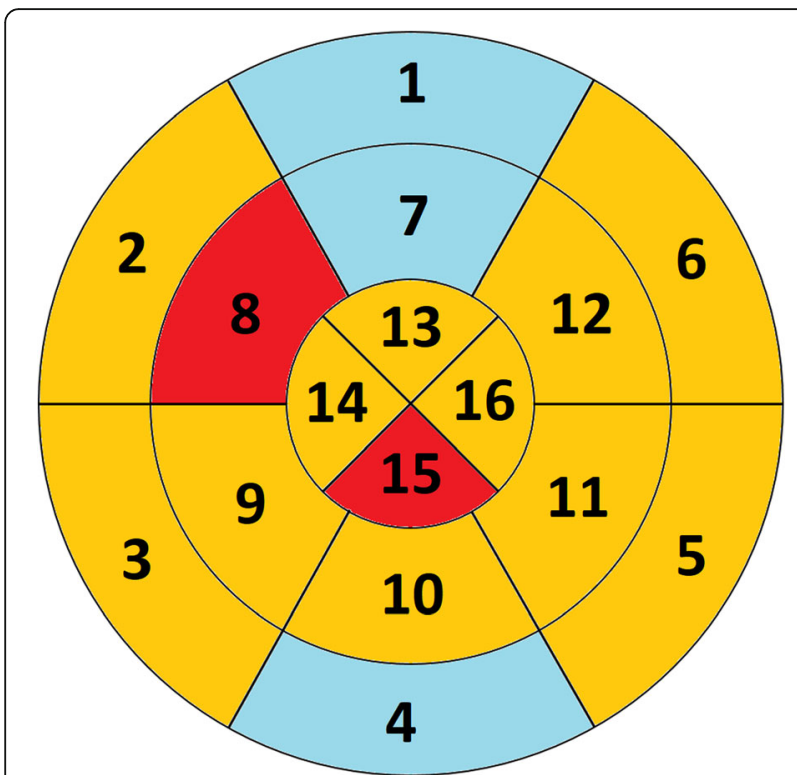

\section{Endocardial layer}

Fig. 3 Segmental analysis of the endocardial layer according to longitudinal strain based on bull's eye representation (16 segment model). Legend. Red for segments with significant decrease in longitudinal strain from baseline to RT +6 months (but not significant after Holm-Bonferroni method for multiple testing on 16 tests); Orange for segments with non-significant decrease in longitudinal strain; Blue for segments with non-significant increase in longitudinal strain

\section{Difference of strain according to myocardial layers}

The LS difference according to the myocardial layers that we observed in either baseline or $\mathrm{RT}+6$ months values, with higher values in the endocardial layer and lower values in the epicardial layer, has been previously observed [26]. In normal heart, contraction is greater in the endocardial layer than in the epicardial layer [27] and the difference in amplitude of myocardial contraction between the endocardial and epicardial regions is related to the orientation pattern of myocardial fiber in the heart as the subendocardium is predominantly composed of longitudinal myocardial fiber. Moreover, the longitudinal left ventricular mechanics are predominantly governed by the subendocardial layer of the myocardium, which may explain the significant decrease in global LS from baseline to RT +6 months visits in the three layers. However, with greater contraction and higher energy requirements, endocardial layer is more susceptible to injury which may explain that the relative decrease in LS was slightly higher in the endocardial layer.

\section{Location of LS deterioration}

Unlike chemotherapy, which impact on myocardial function can be considered global at the scale of the left ventricle, RT affects the heart in a more localized way as the apical level of the left ventricle is particularly exposed to the tangential beams of the RT [19]. This may explain the strongest decrease of the LS at the apical level as previously observed [6]. Moreover, in a previous study of patients with left-sided breast cancer [12], the segments with a significant strain reduction just after RT and 3 years post-RT were similar to those found in our study, particularly with regards to the mid-anterolateral segment and the apical-inferior segment. However, the association between LS decrease and cardiac dose is far to be clear and our correlations between LS decrease and doses to the different cardiac structures were low (under 0.3), as previously observed in several other studies $[6,10,11]$.

Concerning the coronary arteries territorial analysis of LS, we found significant deterioration of the LS for the LAD. The strongest impact on the LAD territory could be explained by the fact that the segments related to this coronary artery received highest radiation doses [19]. Moreover, patients with the highest LAD doses ( $>20 \mathrm{~Gy}$ ) were those with a clear LS deterioration as illustrated in Fig. 3.

\section{LS of the endocardial layer and LAD territory}

It is commonly accepted that the endocardium is the most susceptible target to ischemic injury $[28,29]$. Moreover, it has been shown that LS of the endocardial

Table 4 Territorial analysis of longitudinal strains in the endocardial layer for the coronary arteries

\begin{tabular}{|c|c|c|c|c|c|}
\hline & & \multicolumn{2}{|c|}{ Low dose to the LV $\boldsymbol{N}=42$} & \multicolumn{2}{|c|}{ High dose to the LV $\boldsymbol{N}=22$} \\
\hline & & $\overline{v 0}$ & V6 & $\overline{v 0}$ & V6 \\
\hline \multirow[t]{2}{*}{ TLS - LAD, \% } & Mean \pm SD & $-22.9 \pm 4,3$ & $-21.8 \pm 5,0$ & $-22.7 \pm 3.4$ & $-20.7 \pm 4.5$ \\
\hline & $p$-value & 0.20 & & $0.05^{\mathrm{a}}$ & \\
\hline \multirow[t]{2}{*}{ TLS - Cx, \% } & Mean \pm SD & $-19.0 \pm 4.9$ & $-17.5 \pm 5.1$ & $-19.5 \pm 3.8$ & $-17.9 \pm 5.5$ \\
\hline & $p$-value & 0.10 & & 0.25 & \\
\hline \multirow[t]{2}{*}{ TLS - RCA, \% } & Mean \pm SD & $-16.2 \pm 4.7$ & $-16.2 \pm 5.2$ & $-16.9 \pm 4.8$ & $-15.6 \pm 5.1$ \\
\hline & $p$-value & 0.97 & & 0.35 & \\
\hline
\end{tabular}

Left Ventricle; TLS Territorial Longitudinal Strain, LAD Left Anterior Descending artery, CX Circumflex artery, RCA Right Coronary Artery. Low dose to the LV corresponds to patients receiving $<8.6 \mathrm{~Gy}$ to the LV (66th percentile of dose distribution among the 64 patients). High dose to the LV corresponds to patients receiving $>8.6 \mathrm{~Gy}$. ${ }^{a}$ Not significant after Holm-Bonferroni method for multiple testing 


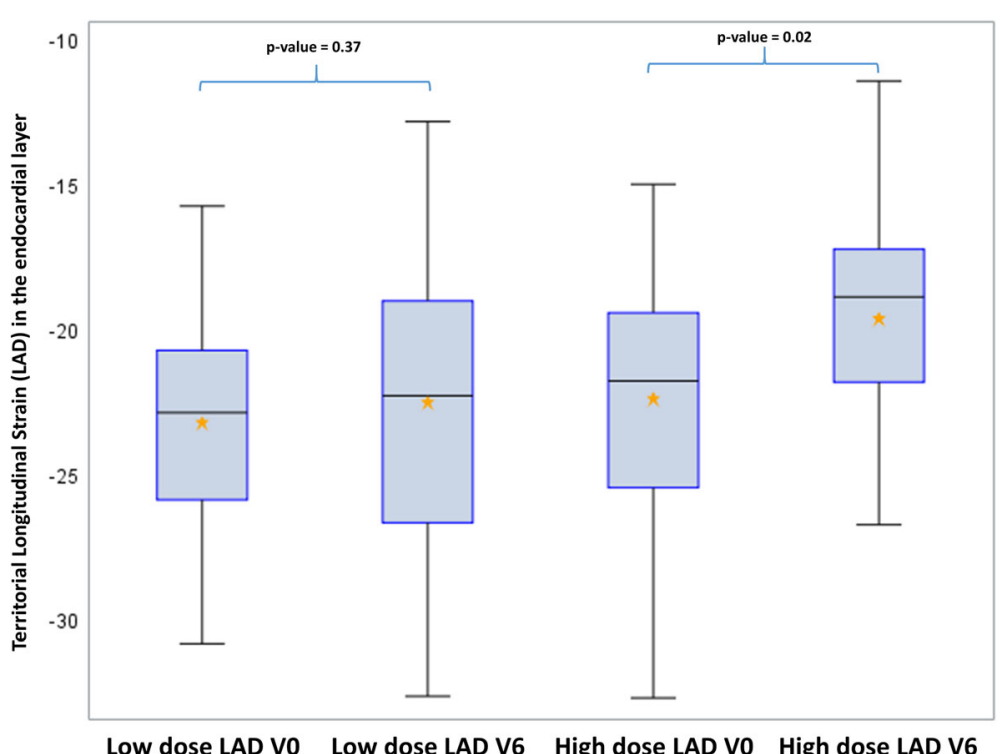

Fig. 4 Longitudinal strain in the endocardial layer for the $L A D$ territory according to the exposure level of the $L A D$. Legend: $L A D=L$ Left $A n t e r i o r$ Descending artery; High dose for patients with LAD dose > 19.9 Gy; Low doses for patients with LAD dose $<19.9$ Gy). V0 = Baseline; V6 = 6 months after radiotherapy. NB: After Holm-Bonferroni method for multiple testing (2 tests), the $p$-value of 0.02 remain significant

layer was superior to other layers to identify significant coronary artery disease [16]. On the other hand, previous researches pointed toward a relationship between the location of coronary stenosis and radiation dose after RT, primarily at the LAD [30-33]. Our results indicated that the impact of RT on LS could be observed particularly in the endocardial layer within the LAD territory, which is concordant with these previous publications.
LAD is known to be the most affected coronary artery with long term follow up after BC RT. Therefore, although LS is not a direct marker of coronary artery disease, a significant deterioration of endocardial layer LS in the segments of the LAD territory with a short follow-up could be a potential marker of other cardiac disease such as an early marker of potential more severe injury in the LAD.

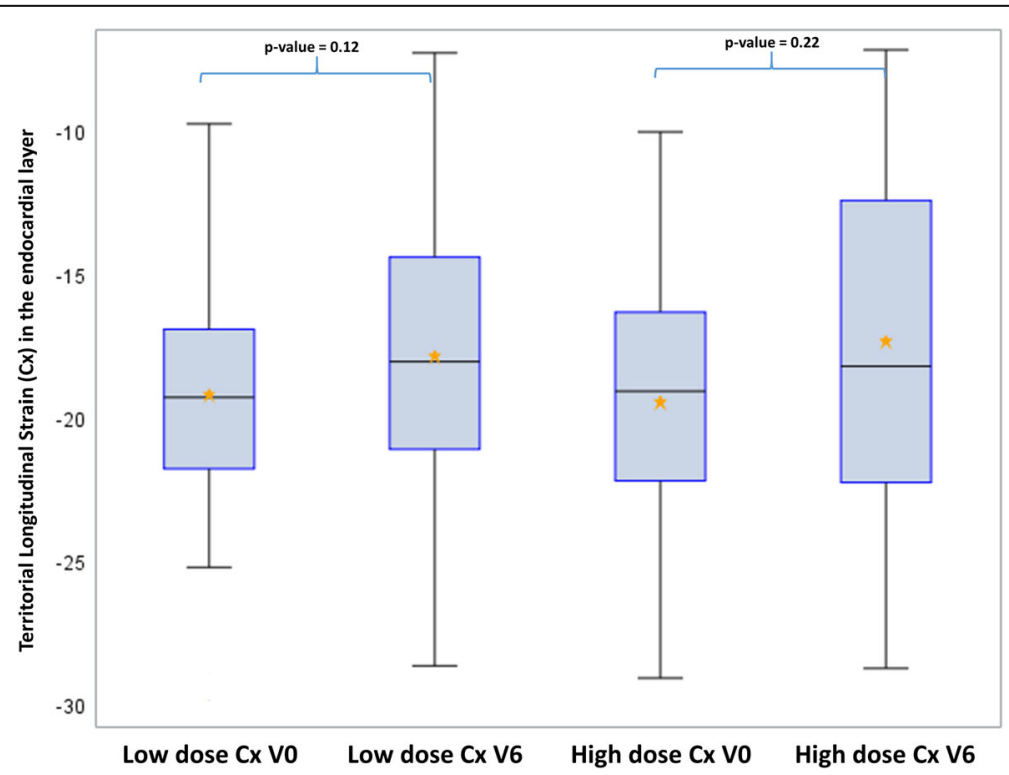

Fig. 5 Longitudinal strain in the endocardial layer for the $C x$ territory according to the exposure level of the Cx. Legend: $C x=C$ ircumflex artery; High dose for patients with LAD dose $>1.8 \mathrm{~Gy}$; Low doses for patients with LAD dose $<1.8 \mathrm{~Gy}$ ). $V 0=$ Baseline; $V 6=6$ months after radiotherapy 


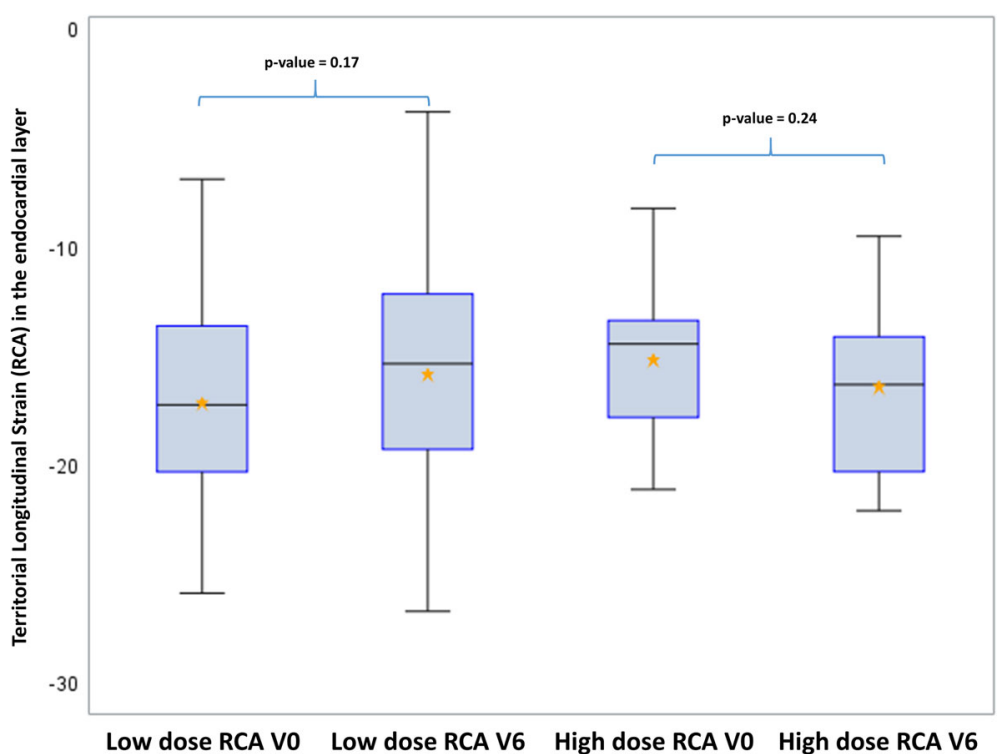

Fig. 6 Longitudinal strain in the endocardial layer for the RCA territory according to the exposure level of the RCA. Legend: RCA = Right Coronary Artery; High dose for patients with LAD dose $>0.8 \mathrm{~Gy}$; Low doses for patients with LAD dose $<0.8 \mathrm{~Gy}$ ). V0 = Baseline; V6 $=6$ months after radiotherapy

\section{Limitations}

Several limitations should be mentioned. The first point is not specific of our study, but a general limitation of global LS to know how the changes in LS might translate into clinical cardiac outcome parameters (morbidity/mortality). In the context of chemotherapy, it has been showed that there is a correlation and a predictive value of GLS decrease on the later presence of the outcome CTRCD (Cancer Therapeutics-Related Cardiac Dysfunction) defined by a decrease in LVEF of at least $10 \%$ to a value $<53 \%$ [4]. However, such CTRCD may be reversible in some cases and do not translate into clinical cardiac morbidity. Although the decrease in longitudinal strain and LVEF appears to at least partially persist throughout the treatment it is unknown what their evolution will be in subsequent years, and whether early deformation measurements will predict persistent decreases in LVEF or symptomatic heart failure. In the context of general population, a wide Danish study established that lower GLS was associated with a higher risk of a composite endpoint defined by incident heart failure, acute myocardial infarction or cardiovascular death (HR 1.12 [1.08-1.17], $p<0.001$ per $1 \%$ decrease) [34]. In the context of radiotherapy, it is still unknown whether changes in LS will translate into clinical cardiac morbidity or mortality. In summary, based on different studies in different contexts, use of GLS measurement in the specific context of radiotherapy-treated patients is more and more frequent as an additional parameter (in particular to
LVEF) to potentially predict later cardiac morbi/mortality, but it has still to be investigated and validated in observational studies with long follow-up. As a second limitation, our study is a prospective study but based on short follow-up and a relatively small population of left-sided $\mathrm{BC}$ patients, which did not provide information on the value of specific myocardial deformation parameters in the prognosis of cardiac complication, in particular injury to the LAD. Further studies with clear clinical endpoints will be required to determine the clinical significance of our findings. In particular, the observation of decreased LS in the LAD territory as well as in the apical region of the left ventricle should be compared with observations from computed tomography coronary angiography analysis [19, 31]. Furthermore, multi-layer strain analysis is controversial [35], limited by poor reproducibility and important variability [26]. Our results were exploratory and should be confirmed by other studies.

\section{Conclusions}

With a follow-up of 6 months after RT, LS decrease was predominantly in the endocardial myocardial layer and appeared to be localized in the most exposed part of the left ventricle. For precise evaluation of RT-induced cardiotoxicity and early left ventricular dysfunction, the endocardial layer-based LS might be the most sensitive parameter, in particular to evaluate the impact of radiation exposure during $\mathrm{BC}$ RT to the LAD. However, this exploratory analysis remains to be confirmed with larger studies and longer follow-up. 


\section{Abbreviations}

3D-CRT: Three-Dimensional Conformal Radiation Therapy; Cx: Circumflex artery; LAD: Left Anterior Descending coronary artery; LS: Longitudinal Strain; LVEF: Left Ventricular Ejection Fraction; RCA: Right Coronary Artery; RT: Radiotherapy (or Radiation Therapy)

\section{Acknowledgements}

Not applicable.

\section{Authors' contributions}

Conceived study: SJ, WW, OL, GJ, MOB, DL, JF. Data analysis: OL, OF, GJ, JC, LP, DB, JF, SJ. Statistical analysis: WW, MOB, JF, DL, SJ. All authors participated in the writing, and manuscript edition. All authors read and approved the final manuscript.

\section{Authors' information}

Not applicable.

\section{Funding}

The study received funding for collection of data from the Fédération Française de Cardiologie (FFC), from Electricité de France (EDF) and from the H2020 Euratom research and training program 2014-2018 under grant agreement No 755523 in the frame of the MEDIRAD project.

\section{Availability of data and materials}

The datasets used and/or analysed during the current study are available from the corresponding author on reasonable request.

\section{Ethics approval and consent to participate}

This study received ethical approval from the French South West Committee for Protection of Persons (ID: CPP2015/66/2015-A00990-69) and from National Agency for Medical and Health products Safety (Reference: 150873B-12). All patients enrolled in the study provided their written informed consent.

\section{Consent for publication}

Not applicable.

\section{Competing interests}

Declarations of interest: none.

\section{Author details}

'Pôle Santé-Environnement (PSE-SANTE), Service de recherche sur les effets biologiques et sanitaires des rayonnements ionisants (SESANE), Laboratoire d'épidémiologie des rayonnements ionisants (LEPID), Institute for Radiological Protection and Nuclear Safety (IRSN), BP17, 92262 Fontenay-aux-Roses cedex, France. ${ }^{2}$ Department of Cardiology, Ranqueil University Hospital, 31059 Toulouse, France. ${ }^{3}$ Cardiac Imaging Centre, Rangueil University Hospital, 31059 Toulouse, France. ${ }^{4}$ Medical School of Rangueil, University Paul Sabatier, 31400 Toulouse, France. ${ }^{5}$ Department of Cardiology, Clinique Pasteur, 31300 Toulouse, France. ${ }^{6}$ Department of Radiation Oncology (Oncorad), Clinique Pasteur, 31300 Toulouse, France. ${ }^{7}$ Department of Cardiac Arrhythmia, Clinique Pasteur, 31300 Toulouse, France. ${ }^{8}$ Department of dosimetry, Institute for Radiological Protection and Nuclear Safety (IRSN), Fontenay-aux-Roses, France. ${ }^{9}$ Division of Health and Environment, Institute for Radiological Protection and Nuclear Safety (IRSN), Fontenay-aux-Roses, France. ${ }^{10}$ Medical School of Purpan, University Paul Sabatier, 31000 Toulouse, France. ${ }^{11}$ INSERM, UMR1027, 31000 Toulouse, France.

Received: 23 June 2020 Accepted: 4 August 2020

Published online: 20 August 2020

\section{References}

1. Gagliardi G, Lax I, Rutqvist LE. Partial irradiation of the heart. Semin Radiat Oncol. 2001;11:224-33.

2. Darby SC, Cutter DJ, Boerma M, Constine LS, Fajardo LF, Kodama K, et al. Radiation-related heart disease: current knowledge and future prospects. Int J Radiat Oncol. 2010;76:656-65.
3. Piroth MD, Baumann R, Budach W, Dunst J, Feyer P, Fietkau R, et al. Heart toxicity from breast cancer radiotherapy: current findings, assessment, and prevention. Strahlenther Onkol. 2019;195:1-12.

4. Plana JC, Galderisi M, Barac A, Ewer MS, Ky B, Scherrer-Crosbie M, et al. Expert consensus for multimodality imaging evaluation of adult patients during and after cancer therapy: a report from the American Society of Echocardiography and the European Association of Cardiovascular Imaging. Eur Heart J - Cardiovasc Imaging. 2014;15:1063-93.

5. Thavendiranathan P, Poulin F, Lim K-D, Plana JC, Woo A, Marwick TH. Use of myocardial strain imaging by echocardiography for the early detection of Cardiotoxicity in patients during and after Cancer chemotherapy. J Am Coll Cardiol. 2014;63:2751-68.

6. Erven K, Jurcut R, Weltens C, Giusca S, Ector J, Wildiers H, et al. Acute radiation effects on cardiac function detected by strain rate imaging in breast Cancer patients. Int J Radiat Oncol. 2011;79:1444-51.

7. Erven $K$, Florian A, Slagmolen P, Sweldens $C$, Jurcut $R$, Wildiers $H$, et al. Subclinical Cardiotoxicity detected by strain rate imaging up to 14 months after breast radiation therapy. Int J Radiat Oncol. 2013;85:1172-8.

8. Heggemann F, Grotz H, Welzel G, Dösch C, Hansmann J, Kraus-Tiefenbacher $\mathrm{U}$, et al. Cardiac function after multimodal breast Cancer therapy assessed with functional magnetic resonance imaging and echocardiography imaging. Int J Radiat Oncol. 2015;93:836-44.

9. Sritharan HP, Delaney GP, Lo Q, Batumalai V, Xuan W, Thomas L. Evaluation of traditional and novel echocardiographic methods of cardiac diastolic dysfunction post radiotherapy in breast cancer. Int J Cardiol. 2017;243:204-8.

10. Lo Q, Hee L, Batumalai V, Allman C, MacDonald P, Lonergan D, et al. Strain imaging detects dose-dependent segmental cardiac dysfunction in the acute phase after breast irradiation. Int J Radiat Oncol. 2017;99:182-90.

11. Tuohinen SS, Skyttä T, Poutanen T, Huhtala H, Virtanen V, KellokumpuLehtinen P-L, et al. Radiotherapy-induced global and regional differences in early-stage left-sided versus right-sided breast cancer patients: speckle tracking echocardiography study. Int J Cardiovasc Imaging. 2017;33:463-72.

12. Tuohinen SS, Skytta T, Huhtala H, Virtanen V, Kellokumpu-Lehtinen P-L, Raatikainen P. Left ventricular speckle tracking echocardiography changes among early-stage breast Cancer patients three years after radiotherapy. Anticancer Res. 2019;39:4227-36.

13. Chen L, Ta S, Wu W, Wang C, Zhang Q. Prognostic and added value of echocardiographic strain for prediction of adverse outcomes in patients with locally advanced non-small cell lung Cancer after radiotherapy. Ultrasound Med Biol. 2019;45:98-107.

14. Trivedi SJ, Choudhary P, Lo Q, Sritharan HP, Iyer A, Batumalai V, et al. Persistent reduction in global longitudinal strain in the longer term after radiation therapy in patients with breast cancer. Radiother Oncol. 2019;132: $148-54$.

15. Walker V, Lairez O, Fondard O, Pathak A, Pinel B, Chevelle C, et al. Early detection of subclinical left ventricular dysfunction after breast cancer radiation therapy using speckle-tracking echocardiography: association between cardiac exposure and longitudinal strain reduction (BACCARAT study). Radiat Oncol. 2019;14:204.

16. Sarvari Sl, Haugaa KH, Zahid W, Bendz B, Aakhus S, Aaberge L, et al. Layerspecific quantification of myocardial deformation by strain echocardiography may reveal significant CAD in patients with non-STsegment elevation acute coronary syndrome. JACC Cardiovasc Imaging. 2013;6:535-44.

17. Adamu U, Schmitz F, Becker M, Kelm M, Hoffmann R. Advanced speckle tracking echocardiography allowing a three-myocardial layer-specific analysis of deformation parameters. Eur J Echocardiogr. 2008;10:303-8.

18. Leitman M, Lysiansky M, Lysyansky P, Friedman Z, Tyomkin V, Fuchs T, et al. Circumferential and longitudinal strain in 3 myocardial layers in Normal subjects and in patients with regional left ventricular dysfunction. J Am Soc Echocardiogr. 2010;23:64-70.

19. Jacob S, Camilleri J, Derreumaux S, Walker V, Lairez O, Lapeyre M, et al. Is mean heart dose a relevant surrogate parameter of left ventricle and coronary arteries exposure during breast cancer radiotherapy: a dosimetric evaluation based on individually-determined radiation dose (BACCARAT study). Radiat Oncol. 2019;14:29.

20. Moignier A, Broggio D, Derreumaux S, El Baf F, Mandin A-M, Girinsky T, et al. Dependence of coronary 3-dimensional dose maps on coronary topologies and beam set in breast radiation therapy: a study based on CT angiographies. Int J Radiat Oncol. 2014;89:182-90. 
21. Nilsson G, Witt Nyström P, Isacsson U, Garmo H, Duvernoy O, Sjögren I, et al. Radiation dose distribution in coronary arteries in breast cancer radiotherapy. Acta Oncol. 2016;55:959-63.

22. Lang RM, Badano LP, Mor-Avi V, Afilalo J, Armstrong A, Ernande L, et al. Recommendations for Cardiac Chamber Quantification by Echocardiography in Adults: An Update from the American Society of Echocardiography and the European Association of Cardiovascular Imaging. J Am Soc Echocardiogr. 2015;28:1-39 e14.

23. Jacob S, Pathak A, Franck D, Latorzeff I, Jimenez G, Fondard O, et al. Early detection and prediction of cardiotoxicity after radiation therapy for breast cancer: the BACCARAT prospective cohort study. Radiat Oncol. 2016;11:54.

24. Voigt J-U, Pedrizzetti G, Lysyansky P, Marwick TH, Houle H, Baumann R, et al. Definitions for a common standard for 2D speckle tracking echocardiography: consensus document of the EACVI/ASE/industry task force to standardize deformation imaging. J Am Soc Echocardiogr Off Publ Am Soc Echocardiogr. 2015;28:183-93.

25. Lang RM, Bierig M, Devereux RB, Flachskampf FA, Foster E, Pellikka PA, et al. Recommendations for chamber quantification: a report from the American Society of Echocardiography's guidelines and standards committee and the chamber quantification writing group, developed in conjunction with the European Association of Echocardiography, a branch of the European Society of Cardiology. J Am Soc Echocardiogr. 2005;18:1440-63.

26. Ancedy Y, Ederhy S, Lang S, Hollebecque A, Dufour LS, Adavane-Scheuble S, et al. Multilayer global longitudinal strain in patients with cancer: a comparison of two vendors. Arch Cardiovasc Dis. 2018;111:285-96.

27. Tsutsui H, Uematsu M, Yamagishi M, Haruta S, Shimakura T, Miyatake K. Usefulness of the subendocardial myocardial velocity gradient in low-dose dobutamine stress echocardiography. Heart Vessel. 2000;15:11-7.

28. Duncker DJ, Traverse JH, Ishibashi Y, Bache RJ. Effect of NO on transmural distribution of blood flow in hypertrophied left ventricle during exercise. Am J Physiol-Heart Circ Physiol. 1999;276:H1305-12.

29. Geer JC, Crago CA, Little WC, Gardner LL, Bishop SP. Subendocardial ischemic myocardial lesions associated with severe coronary atherosclerosis. Am J Pathol. 1980;98:18.

30. Correa CR, Litt HI, Hwang W-T, Ferrari VA, Solin L, Harris EE. Coronary artery findings after left-sided compared with right-sided radiation treatment for early-stage breast Cancer. J Clin Oncol. 2007;25:3031-7.

31. Nilsson G, Holmberg L, Garmo H, Duvernoy O, Sjögren I, Lagerqvist B, et al. Distribution of coronary artery stenosis after radiation for breast Cancer. J Clin Oncol. 2012;30:380-6.

32. Zagar TM, Marks LB. Breast Cancer radiotherapy and coronary artery stenosis: location, location, location. J Clin Oncol. 2012;30:350-2.

33. Wennstig A-K, Garmo H, Isacsson U, Gagliardi G, Rintelä N, Lagerqvist B, et al. The relationship between radiation doses to coronary arteries and location of coronary stenosis requiring intervention in breast cancer survivors. Radiat Oncol. 2019;14:40 [cited 2020 Feb 28]. Available from: https://ro-journal.biomedcentral.com/articles/10.1186/s13014-019-1242-z.

34. Tor B-S, Reumert B-SS, Javier OF, Morten S, Godsk JP, Rasmus M, et al. Global Longitudinal Strain by Echocardiography Predicts Long-Term Risk of Cardiovascular Morbidity and Mortality in a Low-Risk General Population. Circ Cardiovasc Imaging. 2017;10:e005521.

35. Orloff E, Fournier P, Bouisset F, Moine T, Cournot M, Elbaz M, et al. Myocardial multilayer strain does not provide additional value for detection of myocardial viability assessed by SPECT imaging over and beyond standard strain. Echocardiography. 2018;35:1300-9.

\section{Publisher's Note}

Springer Nature remains neutral with regard to jurisdictional claims in published maps and institutional affiliations.

Ready to submit your research? Choose BMC and benefit from:

- fast, convenient online submission

- thorough peer review by experienced researchers in your field

- rapid publication on acceptance

- support for research data, including large and complex data types

- gold Open Access which fosters wider collaboration and increased citations

- maximum visibility for your research: over $100 \mathrm{M}$ website views per year

At $\mathrm{BMC}$, research is always in progress.

Learn more biomedcentral.com/submissions 